\title{
DEVELOPMENT OF YOUTH SENSOMOTORIC COORDINATION IN ACQUISITION OF PLAYING PERCUSSION INSTRUMENTS
}

\section{SUMMARY}

Introduction. In playing percussion instruments, the main activity takes place through movement or motorics, it requires a developed sensomotor coordination.

Aim of the Study. Study and verify development of youth's sensomotor coordination in acquisition of playing the percussion instruments.

Materials and Methods. Theory methods - analysis of pedagogical, psychological literature; empiric - testing with Vienna test (SMC), ascertaining and forming experiment, parametric statistic analysis.

Results. The best results of initial SMC tests belong to the group of professional percussion instrument players, on average by 3.22\% worse results were found in the experimental group and by $2 \%$ lower results in comparison to the experimental group were found in the control group. In the repeated SMC tests with the experimental group that exercised coordination of percussion instrument play for 6 months, a significant improvement in the indicator characterising sensomotor coordination abilities was found.

Conclusions. Extended and regular play of percussion instruments, as well regular training at coordination exercises of percussion instrument play prepared by the author of the research even in six months efficiently develop the youth's sensomotor coordination.

Key words: acquisition percussion instrument play, sensomotor coordination, youth

\section{INTRODUCTION}

Methodical approach to play of percussion instruments in each age group is different, but the aim is common - to find the opportunity for youth to feel the emotional experience, to mobilise mental skills, provide them with opportunity to reveal various ways of self-expression. Although the activity takes place in unity with attention, perception, memory and thinking, a coordinated body is needed for its implementation. The main activity takes place through movement or motorics. In practice the motorics is based on automated movements that are formed gradually.

Any intellectual activity promotes development of intellectual skills. Scientific researches stimulates turning to training where intellectual skills are unbound and developed by creative activity through self-expression. By training movements, it is possible not only to release, feel and know one's own body, to get aesthetic experience and develop skills, but also to activate psychic processes, and stimulate specific activity of brain hemisphere. Thus a better brain activation takes place and learning on whole acquires a better quality (Klöppel, 2003; Wiemeyer, 2000; Geiger, 1998; Schachl, 2005).

German scientist W. Jank acquires a confirmation as a result of a research that types of musical activity - singing and playing instruments - are the most efficient means for developing 
skills (Jank, 2005).

Playing music is directed towards educating a person and development of intellect. During the play, a simultaneous activity of many brain zones takes place - perception, attention, movement, sense of rhythm, coordination, hearing, thinking, memory, emotions. Results of previous researches by scientists show that musicians have a different degree of hemisphere dominance in comparison to people who are not musicians. Musicians have a significant left-oriented asymmetry of planum temporale. This is related to the increased communication between brain hemispheres that is formed from motoric movement of both hands (Schlaug, Gaab, 2003).

E. Altenmüller, W. Gruhn, and D. Parlitz have developed a neurobiological principle theory of pedagogy that acquisition of music improves activity of a person's both brain hemispheres efficiently and develops skills (Altenmüller, Gruhn, Parlitz, 1999).

In contradiction to the traditional opinion that the primary function of cerebellum is securing movement coordination, the most recent researches have indicated that activity affects the functions of both the language and cognition, which allows concluding that improvement of movement coordination could stimulate development of cognitive functions (Vicari, Menghini, 2008). This is a very significant finding in the research and provides justification for an assumption that by purposeful training at playing percussion instruments it is possible to develop not only the youths' sensomotor coordination, but also all the other skills - attention, perception, memory, thinking.

\section{AIM OF THE STUDY}

Study and verify development of youth's sensomotor coordination in acquisition of playing the percussion instruments.

\section{MATERIALS AND METHODS}

Playing percussion instruments requires developed skills of movement coordination; therefore we will go into detail about the essence of these skills and possibilities to develop them.

Learning to play music means learning at three levels, namely, learning to think, feel and act or learning at the cognitive, affective and motoric level. Bodily factors - speed, force, movability, endurance and coordination skills cannot be reviewed separately from the mind that regulates movements (Klöppel, 2003).

In acquisition of playing percussion instruments, it is important:

- to achieve relaxed play at various tempos and dynamics;

- to achieve even sound in the play by two hands simultaneously on one and the same instrument;

- to acquire peculiarities of acoustics to be able to foresee sound of the instrument and the corresponding beat before it has been made;

- to land beats on the instrument at the right place and time;

- to plan movements ahead to place accents;

- to be physically relaxed to be able to play by freely performing movements without feeling tiredness during playing music (Dahl, 2006).

A significant condition of motorics is a quick, dimensional and in the sense of time precise coordination of many various separate movements. The basic speed, force of the speed and endurance of the speed, although their meaning is different in play of various instruments, form the components for the basis where the coordination skill is developed.

Next to other skills, preconditions for virtuoso music playing are mobility, speed, force and 
endurance - to a different degree for various instruments. However, during every-day practice these basic conditions are not trained purposefully. In order to create the necessary sound, one must learn and must coordinate many separate movements in detail, where most often both hands and several finders and both legs are needed at the same time, movements that are not regular and therefore brings forward high cognitive demands. This movement organisation at first depends on impulses of the central nervous system that ensures conscious muscle coordination (Klöppel, 2003).

Economic use of muscles during playing music is only one part of movement coordination. This economy makes easy and partially even possible the fulfilment of complex movement. Many separate skills that one and the same person may have developed in a different scope form a set of motoric skills.

By elementary movement figures, in a complicated manner, a large number of muscle groups and separate muscles work together. For this reason, during every training session a pedagogue should stimulate youths to regularly dedicate time for development of this elementary motorics (Gellrich, 1998).

J. Geiger turns to three concepts - bodily conscious play of the instrument and how it can be developed on the basis of the both important components - kinaesthesia (a person's self-perception in bodily and physical sense) and psychomotor domain - motorics that is determined and regulated by emotional and psychic factors and perception while playing the instrument (Geiger, 1998).

Movement coordination is defined by $\mathrm{H}$. Mechling as "management of a separate movement or a set of movements by help of a moderate force in a space that is realised in compliance with sensorially depicted conditions or targets" (Mechling, 1992, 82).

Movement coordination has two important processes of agreement:

- "neuro-muscular coordination - agreement of nerve and muscle activity;

- sensomotor coordination - agreement of sensory and muscle activity within the scope of movements focused on the target as orientating and motivating perception of information, reply information, comparison of the reply information with the planned target and the possible correction" (Mechling, 1992, 82).

In order to understand correspondence with the psychological training and movement coordination, the neuro-physiological and psychological bases of movement coordination were analysed.

"The following parts of central nervous system take part in movement coordination: spinal cord - spinal motorics, brain stem and reticular formation, cerebellum, basal neural nuclei, primary motor cortex, pre-motoric cortex, additional motor cortex." (Wiemeyer, 2000, 117)

Body feeling during playing music is in constant relation with other elements - hearing, vision, play technique, movement, space, imagination, sound, memory that all join together for playing music. Impulse caused by a touch, pressure, temperature and location must be linked together with coordination of sensomotor movements to maintain tactual perception in a form of integrated activity (Geiger, 1998).

Movement coordination can be improved if one can perceive one's own movements and sound resulting from them. As during music playing movement is not a target in itself, it rather helps creating the sound, so it is important to control the hearing whether the movement has been made correctly (see Picture 1). 


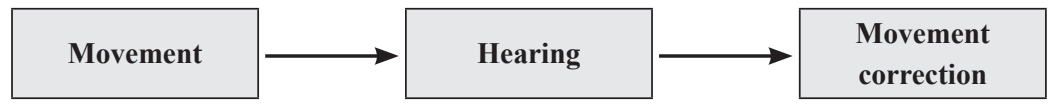

There are many musicians that have never knowingly perceived their movements and feelings that are caused by these movements. It is advisable to ask vision to help: the person, who studies, can see how a good musician performs the movements and by copying him, the pupil can improve his own performance. Kinetic feelings that result from movements are also important.

Picture 2. Movement coordination during music playing (Klöppel, 2003, 96)

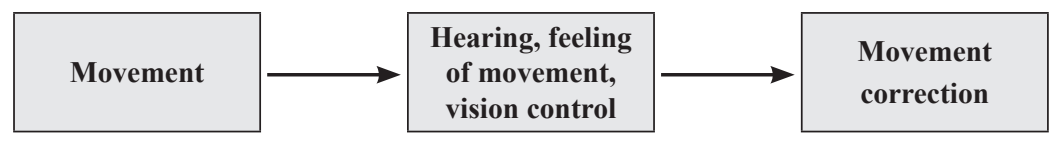

When a musician plays, it can be observed how a play sounds and how it looks, the observer would not be able to see other feelings and senses. Probably, this is the cause why these movement senses and feelings seldom form contents of studies. However, irrespective of individuality, these should also be improved and managed.

As Picture No 2 reveals (see Picture 2), by music playing motoric, cognitive and musical skills are formed, they include also a concept of musical hearing, music playing movements and reading music type that forms a concept of sound that may be turned into a sound, heard or imagined music can be fixed in music type, thinking in concepts makes intellectual understanding of music possible (see Picture 3).

Picture 3. Movement coordination during music playing (Klöppel, 2003, 97)

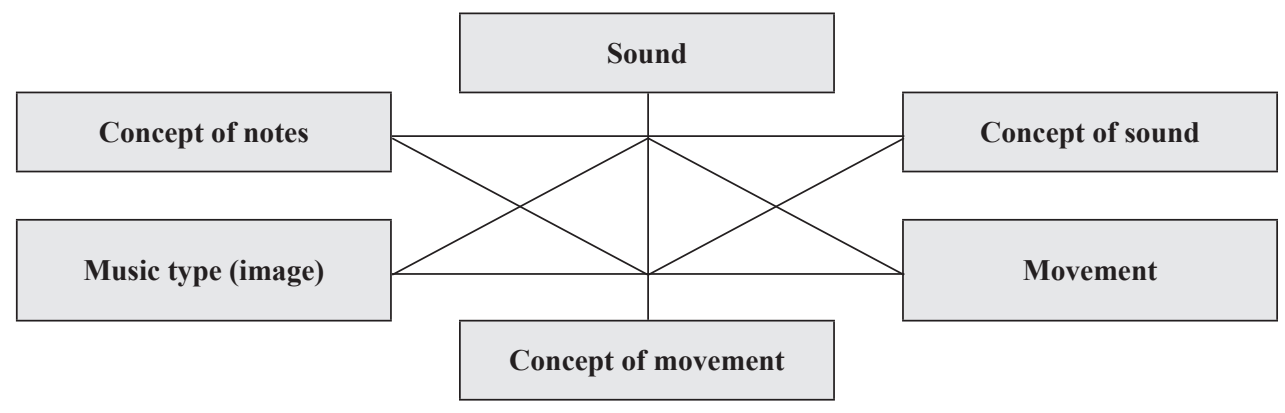

To evaluate the level of youth's sensomotor coordination during acquisition of the percussion play, the research used Vienna test system sensomotor coordination (SMC) S4 test form. 
SMC test is planned for evaluation of a person's sensomotor coordination skills, that is, skills to coordinate movements of both hands and/or hands-legs on the basis of the reciprocal link visually perceived about the precision of one's movements and efficiency by manoeuvring with the geometric that constantly arbitrary moves in the 3-dimensional virtual space. The tests allows evaluation of two separate constructs: 1) sensomotor coordination in an anticipated way ("Anticipative coordination ability") - ability to direct the object towards the pre-planned and known target and 2) sensomotor coordination by adequately reacting towards spontaneous, unpredictable changes of movement trajectory of the object to be directed ("Reactive coordination ability"). The SMC tests allow simultaneous evaluation of both these aspects of sensomotor coordination skills.

\section{RESULTS}

Twenty-seven youths of both genders of the age between 15 and 27 took part in the research, the average age of respondents in the selection - 20. Before starting the research, all participants of the research were informed about the aim of the research, procedure and contents, and voluntarily agreed to participate at the research.

In the initial stage of the pedagogy experiment, an evaluation of sensomotor coordination was carried out in three groups of respondents:

1) participants of the experimental group - persons with basic education in music who began to acquire play of percussion instruments under supervision of the research author, further in the text - "experimental group" $(\mathrm{n}=9)$;

2) "benchmark" control group - persons who play percussion instruments professionally for

5 and more years, further in the text - "benchmark group" $(n=9)$;

3) control group - persons who have never learnt to play percussion instruments, further in the text - "control group" $(n=9)$.

Average results of initial evaluation test of the sensomotor coordination skills (SMC) are reflected in Table 1. The basic variable of the SMC test that characterises most precisely an individual's skill to coordinate movements of the right hand and both legs is the "time in the ideal position (\%)". Comparing the mean average indicators of the variables, it can be seen that the best results belong to the group of professional percussion instrument players, on average by $3.22 \%$ worse results were found in the experimental group and by $2 \%$ lower results in comparison to the experimental group were found in the control group. Respectively:

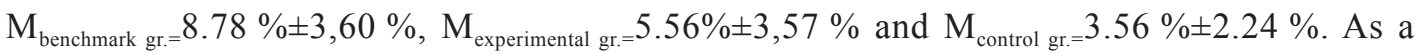
rule, this tendency is maintained also in the other results of variables in this test because "the time in the ideal position (\%)" is the integrative indicator where both the vertical and the horizontal and the angle deviation from the ideal state therefore these indicators will not be reviewed in the text in more detail. The acquired results confirm that a lengthy and regular acquisition of percussion instruments significantly facilitate development of sensomotor coordination skills. There is a basis to foresee that results of this test could be sensitive to events in forming experiment for facilitation of development of sensomotor coordination skill. 
Table 1. Results of initial SMC test in the three groups of respondents. Descriptive statistics

\begin{tabular}{|c|c|c|c|c|}
\hline & & \multicolumn{3}{|c|}{ Respondents'group } \\
\hline & & $\begin{array}{c}\text { Experimental } \\
\text { group }(n=9)\end{array}$ & $\begin{array}{l}\text { Benchmark } \\
\text { group }(n=9)\end{array}$ & $\begin{array}{c}\text { Control } \\
\text { group }(n=9)\end{array}$ \\
\hline \multirow{4}{*}{$\begin{array}{l}\text { The average indicator (in degrees) of } \\
\text { deviation from the right angle in the } \\
\text { SMC test (I) }\end{array}$} & Mean average & 32.02 & 26.57 & 32.73 \\
\hline & Standard deviation & 6.08 & 3.47 & 3.20 \\
\hline & Minimum value & 23.5 & 21.6 & 26.4 \\
\hline & Maximum value & 38.3 & 30.7 & 37.4 \\
\hline \multirow{4}{*}{$\begin{array}{l}\text { Average horizontal deviation (in pixels) } \\
\text { in the SMC test (I) }\end{array}$} & Mean average & 89.36 & 77.70 & 117.24 \\
\hline & Standard deviation & 20.97 & 18.09 & 24.61 \\
\hline & Minimum value & 48.7 & 47.8 & 81.2 \\
\hline & Maximum value & 121.4 & 104 & 149 \\
\hline \multirow{4}{*}{$\begin{array}{l}\text { Average vertical deviation (in pixels) in } \\
\text { the SMC test (I) }\end{array}$} & Mean average & 62.84 & 50.98 & 73.31 \\
\hline & Standard deviation & 18.89 & 11.23 & 16.78 \\
\hline & Minimum value & 36.1 & 40.9 & 47.9 \\
\hline & Maximum value & 92.3 & 76.7 & 106.4 \\
\hline \multirow{4}{*}{$\begin{array}{l}\text { Dispersion of angle deviation (in } \\
\text { degrees) in the SMC test (I) }\end{array}$} & Mean average & 20.17 & 18.44 & 21.03 \\
\hline & Standard deviation & 2.64 & 2.26 & 1.74 \\
\hline & Minimum value & 16.4 & 15.26 & 17.8 \\
\hline & Maximum value & 23.17 & 21.32 & 22.99 \\
\hline \multirow{4}{*}{$\begin{array}{l}\text { Dispersion of horizontal deviation (in } \\
\text { pixels) in the SMC test (I) }\end{array}$} & Mean average & 82.16 & 70.85 & 96.86 \\
\hline & Standard deviation & 18.17 & 16.25 & 21.49 \\
\hline & Minimum value & 44.53 & 41.51 & 54.7 \\
\hline & Maximum value & 107.19 & 90.94 & 117.77 \\
\hline \multirow{4}{*}{$\begin{array}{l}\text { Dispersion of vertical deviation (in } \\
\text { pixels) in the SMC test (I) }\end{array}$} & Mean average & 44.30 & 38.74 & 50.37 \\
\hline & Standard deviation & 9.55 & 4.26 & 5.07 \\
\hline & Minimum value & 28.32 & 32.97 & 41.32 \\
\hline & Maximum value & 56.75 & 45.69 & 56.11 \\
\hline \multirow{4}{*}{$\begin{array}{l}\text { Time in the ideal position (\%) SMC test } \\
\text { (I) }\end{array}$} & Mean average & 5.56 & 8.78 & 3.56 \\
\hline & Standard deviation & 3.57 & 3.60 & 2.24 \\
\hline & Minimum value & 2 & 5 & 1 \\
\hline & Maximum value & 14 & 16 & 8 \\
\hline \multirow{4}{*}{$\begin{array}{l}\text { Maximum time (\%) in the ideal position } \\
\text { in the SMC test (I) }\end{array}$} & Mean average & 15.56 & 25.56 & 10.89 \\
\hline & Standard deviation & 6.39 & 14.13 & 6.09 \\
\hline & Minimum value & 8 & 9 & 4 \\
\hline & Maximum value & 27 & 50 & 25 \\
\hline
\end{tabular}

For more efficient acquisition of the programme of the play of percussion instrument, seven coordination exercises were developed with an increasing degree of difficulty.

Aim of the exercises are integrated to develop the youth's general and special skills - to develop sensomotor coordination skills; develop sense of rhythm; to develop technique of playing the percussion instruments; to develop skills of music interpretation.

Content of the exercises: concentration of attention, stability, distribution, development of switching, speed of thinking, logics, development of flexibility, development of speed of reaction, 
development of successive and simultaneous perception; training of memory; development of anticipation skills - mind prognosis, movement prognosis, precision of fine movements, control, independence, freedom, rhythm, pulse, tempo, development of sense of polymetria, improvement of skills of technique of percussion instrument play, development of self-discipline, will, endurance.

In a repeated evaluation of youth's skills, respondents of only two groups were involved: participants of the experimental group - the same 9 persons with the basic education in music who acquired the play of the percussion instruments and developed coordination exercises for 45 minutes one time per week for a period of 6 months, and the same 9 respondents of the control group that have never learnt to play music instruments.

Results of the repeated tests were analysed in several stages and aspects. For evaluation of dynamics of changes of the youth's skills, results of the initial and repeated tests were compared, by using T-test for comparing the mean average indicators of the mutually dependable selections (Ttest: Paired Samples Test) by using SPSS 16 computer program. Results of both the experimental and the control group were analysed in order to evaluate the dynamics of development of skills as a result of acquiring play of the percussion instruments by regular training at exercises developed by the author.

In order to get correct conclusions, it is significant to find out not only whether there are statistically significant difference between the results of initial and repeated tests within the scope of each separate group, but also whether these differences are statistically significant also in intergroup evaluation, namely, it is important to determine whether there are statistically significant differences in the found differences between the results of the initial and repeated tests in intergroup evaluation. Thus, initially for the variables of each respondent, a difference between the repeated and initial tests was calculated (result of the II test - result of the I test), and afterwards the acquired balance results were summarised, for both groups, indicators of the descriptive statistics were acquired. Analysis included only the basic variable indicators of the tests. For detecting the distinction of differences found in the experimental and control group between the results of the initial and repeated tests, a parametric statistical analysis was used: t-tests for comparison of mutually independent averages of selections ( $t$ test: Independent Samples Test). All calculations were made by SPSS 16 computer program.

\section{Comparison of results of the initial and repeated tests}

Initially, differences in the experimental group were analysed by comparing the average results of the initial and repeated tests in this selection. Results show that sensomotor coordination skills have improved statistically importantly by possibility of 95\%. This is shown by SMC test indicator "time in the ideal position (\%)" and the "maximum time (\%) in the ideal position". During the second test, respondents of the experimental group could hold a movable object in the ideal position on the average by $6.44 \%$ more, in comparison to the first test. It should be noted that this difference is large and statistically significant $(\mathrm{t}=-2.80, \mathrm{p}<0.05)$. The same refers to the difference of the average indicators of the maximum time in the ideal (\%) position - the balance is $13.44 \%(t=-2.45, \mathrm{p}<0.05)$. On the basis of analysis of the acquired results, it can be concluded that participants of the experimental group have significantly improved the sensomotor coordination skills after 6 months of acquisition of play of the percussion instruments. Picture No 4 shows that 8 of 9 respondents of the experimental group have the indicators of the basic average of the SMC test improved, moreover, it should be noted that in 5 cases of the mentioned 8 , these changes were significant, especially for the respondent with the code B1/6 whose difference between the repeated and initial test totals $22 \%$ (see Picture 4 ). 


\section{Time \%}

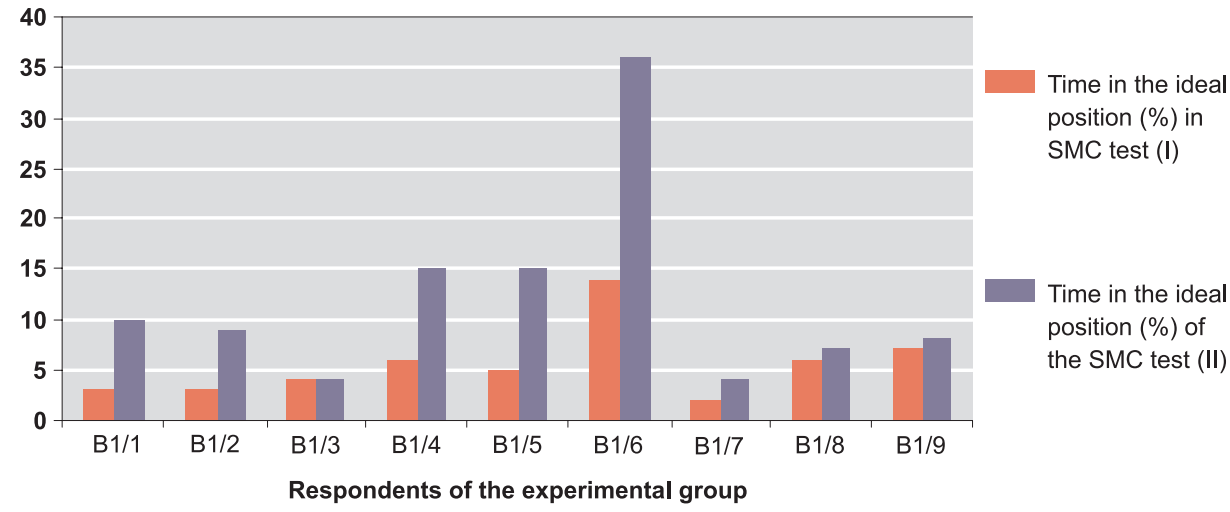

The basic variable "time in the ideal position \%" of the SMC test - in the experimental group, results have statistically significantly improved in comparison to the dynamics of the control group results upon repeated measuring $(\mathrm{t}=2.04, \mathrm{p}<0.06)$. Picture No 5 shows the differences of mean average indicators acquired during the initial and the repeated tests in the experimental and the control group. The acquired results show that in the experimental group, a significant improvement of the indicator characterising the sensomotor coordination skill was found in the experimental group (see Picture 5).

Picture 5. Mean average indicators of the basic variable "time in the ideal position" of the initial and repeated tests of the SMC test of the experimental and the control group

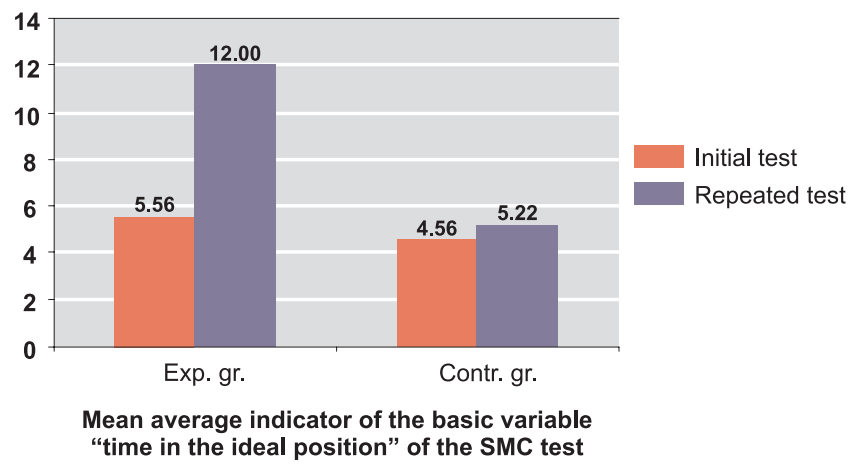

Mutually comparing changes of results found in the experimental and the control group, it can be concluded that the sensomotor coordination skill was improved to a larger extent (with possibility of $95 \%$ ) in the experimental group in comparison to the control group.

\section{CONCLUSIONS}

- Results of the benchmark control group (persons who play the percussion instruments professionally for 5 and more years) acquired during the initial tests confirm that lengthy and regular play of the percussion instruments significantly facilitates development of sensomotor coordination skills. 
- During the repeated tests that took place in six months, results of the basic variable "time in the ideal position \%" in the experimental group have improved statistically significantly in comparison to the dynamics of results from the control group that prove that regularly acquiring the play of the percussion instrument coordination developed by the research author efficiently develop the youth's sensomotor coordination.

- During acquisition of play of the percussion instruments, a pedagogue should take into account the individual traits, skills and problems of a youth's personality so that the development of the sensomotor coordination would happen more successfully as a precondition for expression of youth's personality and musical skills.

\section{REFERENCES}

1. Altenmüller, E., Gruhn, W., Parlitz, D. (1999) Was bewirkt musikalisches Lernen in unserem Gehirn? [How to Achieve Musical Learning of our Brain]. In: H. G. Bastian, (Hrg.) Musik begreifen. Künstlerische Ausbildung und Identitätsfindung [Comprehension of Music. Artistic Learning and Finding of Identity]. Mainz: Schott Musik International, S. 120-143 (in German).

2. Dahl, S. (2006) Movements and Analysis of Drumming. In: Altenmüller, E., Wiesendanger, M., Kesselring, J. (Ed.) Music, Motor Control and the Brain. Oxford University Press, p. 125-138.

3. Geiger, J. (1998) Körperbewusstsein bei Instrumentalspiel auf der Grundlage einer entwickelten Kinästhesie und Psychomotorik [Sense of Body during Playing Instruments as a Basis for Kinaesthetic and Psychomotor Development]. In: G. Mantel, (Hrg.) Ungenutzte Potentiale: Wege zu konstruktivem Üben [Obtained Potential: the Way to Constructive Exercising]. Mainz: Schott Musik International, S. 179-198 (in German).

4. Gellrich, M. (1998) Über den Aufbau motorischer Schemata bei Instrumentalspiel [About the Structure of Motor Scheme of Instrument Playing]. In: G. Mantel, (Hrg.) Ungenutzte Potentiale: Wege zu konstruktivem Üben [Obtained Potential: the Way to Constructive Exercising]. Mainz: Schott Musik International, S. 131-151 (in German).

5. Jank, W. (2005) Musik - Didaktik [Didactics of Music]. Berlin: Cornelsen Verlag Scriptor GmbH\&Co. KG, S. 256 (in German).

6. Klöppel, R. (2003) Die Kunst des Musizierens [The Arts of Playing Music]. Mainz: Schott Musik International, S. 288 (in German).

7. Mechling, H. (1992) Bewegungskoordination [Coordination of Motions]. In: P. Roethig (Ltg.) Sportwissenschaftliches Lexikon [Lexicon of Science of Sports]. Schorndorf, S. 82-83 (in German).

8. Schachl, H. (2005) Was haben wir im Kopf? [What have We got in our Heads?]. Linz: Veritas - Verlag, S. 166 (in German).

9. Schlaug, G., Gaab, N. (2003) Das musizierende Gehirn: Strukturelle und funktionelle Unterschiede zwischen Musikern un Nicht - Musikern [Brains of Playing Music: Structural and Functional Differences between Musicians and Non-Musicians]. In: H. G. Bastian, G. Kreutz (Hg.) Musik und Humanität: Interdisziplinaere Grundlagen fuer (musikalische) Erziehung und Bildung [Music and Humanity: Interdisciplinary Basis for (Musical) Upbringing and Education]. Mainz: Schott Musik International, S. 120-134 (in German).

10. Vicari, S., Menghini, D. (2008) Language and Learning Disabilities. In: Theses of First Meeting of the Federation of the European Societies of Neuropsychology (ESN). Edinburgh, 2-5 September 2008, p. 93. 
11. Wiemeyer, J. (2000) Psychologische Trainingsmethoden und Bewegungskoordination [Method of Psychological Training and Co-ordination of Motions]. In: G. Mantel, (Hrg.) Qverbindungen: Anstösse zur Erweiterung Musikpedagogischer Spielräume [Cross bonds: The Impulses for Widening the Space for Music Pedagogy]. Mainz: Schott Musik International, S. 116-132 (in German).

Dr. paed. Tālis Gžibovskis

Riga Teacher Training and Educational Management Academy

Address: Imantas 7. līnija 1, Rīga, LV - 1083

Phone: +37129265151

Fax: +371 67808034

E-mail: talis.drum@inbox.lv

Prof. Dr. paed. Māra Marnauza

Riga Teacher Training and Educational Management Academy

Address: Imantas 7. līnija 1, Rīga, LV - 1083

Phone: +371 29461145

Fax: +37167808034

E-mail: mara.marnauza@choir.lv

Dr. biol. Daina Voita

Riga Teacher Training and Educational Management Academy

Address: Imantas 7. līnija 1, Rīga, LV - 1083

Phone: +371 26872012

Fax: +37167528258

E-mail:dvoita@mits.lv

Mg. psych. Viktorija Perepjolkina

Riga Teacher Training and Educational Management Academy

Address: Imantas 7. līnija 1, Rīga, LV - 1083

Phone: +371 67860679

Fax: +37167808034

E-mail: viktorija@rpiva.lv 